\title{
PERUMUSAN PERENCANAAN PENGEMBANGAN SEKOLAH BERBASIS SUMBER DAYA PLANNING CONCEPTUAL SCHOOL IMPROVEMENT BASED ON RESOURCES VIEW
}

\author{
Deviya Aprilman ${ }^{1)}$, Gendut Suprayitno ${ }^{2)}$, Kartiko Eko Putranto ${ }^{3)}$ \\ ${ }^{1}$ Mahasiswa Program Studi Magister Teknologi Industri Sekolah Pasca Sarjana ISTN Jakarta. \\ ${ }^{2}$ Dosen Program Studi Magister Teknik Industri Sekolah Pasca Sarjana ISTN Jakarta. \\ ${ }^{3}$ Dosen Program Studi Magister Teknik Industri Sekolah Pasca Sarjana ISTN Jakarta.
}

\begin{abstract}
ABSTRAK
Sekolah merupakan factor penentu terhadap kemajuan bangsa, kalau sekolah maju maka negara akan menjadi maju, kerena bidang ilmu dimulai dari pendidikan, untuk memenuhi kebutuhan pendidikan dan ilmu agama sekolah islam terpadu harus ada di tengah-tengah masyarakat dan berkembangSekolah islam terpadu menyelenggarakan pendidikan dengan kurikulum pendidikan nasional dan kurikulum keagamaan dengan porsi yang seimbang, sehingga selain menciptakan generasi cerdas unggul juga akhlak mulia.Penelitian ini dilakukan untuk melihat tingkat pelaksanaan standar nasional pendidikan untuk mengembangkan sekolah berbasis sumber daya, guna untuk menyediakan layanan pendidikan berbasis ilmu pengetahuan dan keagamaan. Dalam pengmbangan sekolah ini menggunakan metode VRIO (analisis internal berbasis sumber daya). Untuk menghubungkan factor internal dan eksternal menggunakan analisa SWOT kemudian diolah menggunakan aplikasi AHP dalam menetukan bobot penilaian, dari hasil ini untuk menetukan strategi dalam mengembangkan sekolah islam terpadu di kec. Tapos, Kota Depok.
\end{abstract}

Kata kunci: Sekolah Islam terpadu, VRIO, SWOT, AHP

\section{PENDAHULUAN}

Seiring berkembangnya kebutuhan akan pendidikan yang baik maka penyelenggara pendidikan harus mampu memberikan pelayanan pendidikan sesuai dengan yang diinginkan oleh masyarakat, oleh karena itu sekolah islam terpadu (SIT) sebagai penyelenggaran pendidikan harus memberikan pelayanan terbaik sesusai dengan kebutuhan masyarakat saat ini. Untuk mewujudkan hal ini SIT perlu menerapkan standar nasional pendidikan untuk bisa menjadi sekolah unggul berkarakter islam.

Berdasarkan tujuan Pendidikan (Kemdiknas): "Undang-Undang Nomor 20 tahun 2003 tentang Sistem Pendidikan Nasional, Pasal 3, tujuan pendidikan nasional adalah mengembangkan potensi peserta didik agar menjadi manusia yang beriman dan bertakwa kepada Tuhan Yang Maha Esa, berakhlak mulia, sehat, berilmu, cakap, kreatif, mandiri, dan menjadi warga negara yang demokratis serta bertanggung jawab.
Sejalan dengan itu, pada periode 20102014, Kementerian Pendidikan Nasional menetapkan visi Terselenggaranya Layanan Prima Pendidikan Nasional untuk Membentuk Insan Indonesia Cerdas Komprehensif. Insan Indonesia cerdas komprehensif adalah insan yang cerdas spiritual, cerdas emosional, cerdas sosial, cerdas intelektual dan cerdas kinestetis.

\section{DASAR TEORI}

\section{A. Analisis SWOT (IFAS/EFAS/SFAS)}

SWOT analisis (alternatif matriks SWOT) adalah inisialisasi untuk kekuatan (strength), kelemahan (weakness), peluang (opportunity), dan ancaman (threat) yang merupakan metode perencanaan terstruktur yang mengevaluasi empat elemen dari proyek atau usaha bisnis. Sebuah analisis SWOT dapat dilakukan untuk produk, tempat, industri, atau orang. Ini melibatkan menentukan tujuan dari usaha bisnis atau proyek dan mengidentifikasi faktor internal (Internal Factor Analysis 
Summary disingkat dengan IFAS) dan eksternal (External Factor Analysis Summary disingkat dengan EFAS) yang menguntungkan dan tidak menguntungkan untuk mencapai tujuan itu. Beberapa penulis kredit SWOT untuk Albert Humphrey, yang memimpin sebuah konvensi di Stanford Research Institute (sekarang SRI International) pada tahun 1960 dan 1970-an dengan menggunakan data dari perusahaan Fortune 500. Namun, Humphrey sendiri tidak mengklaim penciptaan SWOT, dan asal-usul tetap tidak jelas. Sejauh mana lingkungan internal perusahaan sesuai dengan lingkungan eksternal dinyatakan oleh konsep cocok strategis.

\section{METODE DAN TEKNIK PENGUKURAN}

\section{A. Kerangka Penelitian}

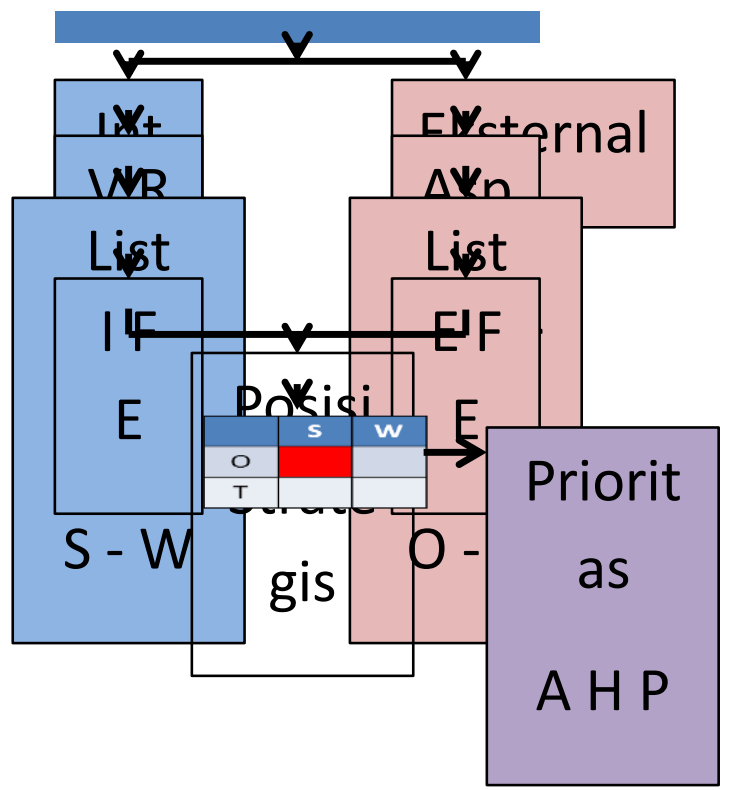

Gambar 1 : kerangka penelitian sekolah berbasis sumber daya

\section{B.Tahap penyusunan model strategi}

Model strategi disusun setelah diperoleh informasi posisi strategis dan elemen kunci strateginya dengan menggunakan A'SWOT.

\section{C.Pengumpulan Data}

Responden pakar yang digunakan pada penelitian ini berasal dari kalangan pakar pendidikan di daerah yakni : (1) Kepala UPT pendidikan kecamatan ; (2) pengawas sekolah; (3) kepala sekolah; (4) guru senior dengan pengelaman lebih dari 10 tahun. Responden pakar ditentukan berdasarkan pengalaman, kewenangan, profesionalisme dan integritas terhadap pengembangan sekolah di kecamatan Tapos Kota Depok. Data yang digunakan dalam penelitian ini meliputi data primer dan sekunder. Data primer diperoleh melalui: (1) pengamatan langsung; (2) penyebaran kuesioner; (3) wawancara mendalam. Sedangkan data sekunder dikumpulkan dengan cara mempelajari data beberapa sekolah. Berikut penjelasan teknik pengumpulan data pada masing-masing tahap :

\section{D.Pengumpulan data penelitian}

1. Pengelompokan sumber daya internal sekolah

Tabel 1 : Pengelompokan sumber daya internal sekolah 


\begin{tabular}{|c|c|c|}
\hline aspek & Kekuatan & Kelemahan \\
\hline Pembiayaan & $\begin{array}{l}\text { Investasi sarana } \\
\text { dan prasarana }\end{array}$ & $\begin{array}{l}\text { Anggaran } \\
\text { pengembangan } \\
\text { guru }\end{array}$ \\
\hline $\begin{array}{l}\text { Penilaian } \\
\text { Pendidikan }\end{array}$ & $\begin{array}{l}\text { Informasi dan } \\
\text { kriteria penilaian }\end{array}$ & $\begin{array}{l}\text { Laporan hasil } \\
\text { penilaian } \\
\text { pembelajaran }\end{array}$ \\
\hline $\begin{array}{l}\text { Pendidik dan } \\
\text { Tenaga } \\
\text { Kependidikan, }\end{array}$ & $\begin{array}{l}\text { Guru dengan } \\
\text { kompetensi yang } \\
\text { sesuai }\end{array}$ & $\begin{array}{l}\text { Kepala } \\
\text { sekolah } \\
\text { dengan } \\
\text { manajerial } \\
\text { inovatif }\end{array}$ \\
\hline Standar Isi & & $\begin{array}{l}\text { Program } \\
\text { pengembangan } \\
\text { kurikulum dan } \\
\text { mata pelajaran }\end{array}$ \\
\hline $\begin{array}{l}\text { Kompetensi } \\
\text { Lulusan, }\end{array}$ & $\begin{array}{l}\text { Mampu } \\
\text { melaksanankan } \\
\text { agama dan akhlak } \\
\text { mulia }\end{array}$ & $\begin{array}{l}\text { Menggunakan } \\
\text { informasi dan } \\
\text { pengalaman } \\
\text { belajar }\end{array}$ \\
\hline $\begin{array}{l}\text { Pengelolaan } \\
\text { pendidikan }\end{array}$ & $\begin{array}{l}\text { 1. Bekerja } \\
\text { sesuai dengan visi } \\
\text { dan misi lembaga } \\
2 . \quad \text { Mengelola } \\
\text { sarana dan } \\
\text { prasarana sekolah }\end{array}$ & $\begin{array}{l}\text { System } \\
\text { informasi } \\
\text { manajemen } \\
\text { yang } \\
\text { mendukung } \\
\text { pendidikan }\end{array}$ \\
\hline $\begin{array}{l}\text { Sarana dan } \\
\text { Prasarana, }\end{array}$ & $\begin{array}{l}\text { Sarana dan } \\
\text { prasarana yang } \\
\text { memadai }\end{array}$ & \\
\hline $\begin{array}{l}\text { Proses } \\
\text { Pendidikan }\end{array}$ & $\begin{array}{l}\text { Rencana program } \\
\text { pembelajaran } \\
\text { yang khas }\end{array}$ & $\begin{array}{l}\text { Evaluasi } \\
\text { kegiatan } \\
\text { pembelajaran }\end{array}$ \\
\hline
\end{tabular}

\section{Pengelompokan sumber daya eksternal sekolah}

Tabel 2 : pengelompokan sumber daya eksternal sekolah

\begin{tabular}{|c|c|c|}
\hline aspek & Peluang & Ancaman \\
\hline $\begin{array}{l}\text { Peraturan dan } \\
\text { Regulasi }\end{array}$ & $\begin{array}{l}\text { Undang-undang } \\
\text { sikdisnas, peraturan } \\
\text { pemerintah dan } \\
\text { peraturan daerah }\end{array}$ & $\begin{array}{l}\text { Kurang } \\
\text { optimalnya } \\
\text { dukungan dan } \\
\text { evaluasi dari } \\
\text { stake holders }\end{array}$ \\
\hline $\begin{array}{l}\text { Kelembagaan } \\
\text { atau yayasan } \\
\text { pengelola }\end{array}$ & $\begin{array}{l}\text { Dukungan yayasan } \\
\text { yang sangat besar } \\
\text { terhadap } \\
\text { pengembangan }\end{array}$ & $\begin{array}{l}\text { Pelaksanaan } \\
\text { sekolah gratis }\end{array}$ \\
\hline $\begin{array}{l}\text { Akses } \\
\text { terhadap } \\
\text { pembiayaan }\end{array}$ & $\begin{array}{l}\text { 1. Pembiayaan } \\
\text { yang cukup untuk } \\
\text { pengembangan } \\
\text { sekolah } \\
2 . \quad \text { Menarik } \\
\text { investasi dari luar } \\
\text { untuk pengembangan }\end{array}$ & $\begin{array}{l}\text { Sekolah } \\
\text { berbiaya } \\
\text { mahal }\end{array}$ \\
\hline $\begin{array}{l}\text { Teknologi } \\
\text { informasi dan } \\
\text { komunikasi }\end{array}$ & $\begin{array}{l}\text { Pemanfaatan } \\
\text { teknologi informasi } \\
\text { dan komunikasi } \\
\text { dalam KBM dan } \\
\text { pelaporan hasil } \\
\text { belajar dan keuangan }\end{array}$ & $\begin{array}{l}\text { Kemudahan } \\
\text { mengakses } \\
\text { internet }\end{array}$ \\
\hline kebijakan & $\begin{array}{l}\text { Dukungan pemerintah } \\
\text { daerah dalam } \\
\text { mengembangkan } \\
\text { sekolah }\end{array}$ & $\begin{array}{l}\text { Kegiatan } \\
\text { ekstrakurikuler } \\
\text { yang kurang } \\
\text { mendukung }\end{array}$ \\
\hline $\begin{array}{l}\text { Lokasi } \\
\text { sekolah }\end{array}$ & $\begin{array}{l}\text { Lokasi yang strategis } \\
\text { dan kemudahan akses }\end{array}$ & \\
\hline $\begin{array}{l}\text { Kebutuhan } \\
\text { pendidikan } \\
\text { dan sekolah }\end{array}$ & $\begin{array}{l}\text { 1. Meningkatnya } \\
\text { jumlah penduduk } \\
2 . \quad \text { Meningkatnya } \\
\text { peminat terhadap } \\
\text { sekolah dengan } \\
\text { kurikulum yang khas }\end{array}$ & $\begin{array}{l}\text { Ketidak } \\
\text { mampuan } \\
\text { dalam } \\
\text { memenuhi } \\
\text { keinginan } \\
\text { warga sekolah }\end{array}$ \\
\hline
\end{tabular}

\section{E.Pengolahan Data}

Data yang diperoleh baik berupa data primer maupun sekunder diolah melalui beberapa teknik melalui langkah-langkah berikut ini :

\section{Pengolahan data penelitian Waktu dan Tempat Penelitian}

Penelitian dilakukan di kecamatan Tapos kota Depok mulai dari bulan Januari sampai dengan Agustus 2014, sedangkan kegiatan wawancara responden pakar dilaksanakan pada bulan September 2014.

\section{Analisis VRIO Faktor Internal Sekolah}

Tabel 3 : Analisis VRIO factor internal Sekolah 


\begin{tabular}{|c|c|c|c|c|c|c|c|c|}
\hline $\begin{array}{l}\mathbf{N} \\
\mathbf{0}\end{array}$ & $\begin{array}{c}\text { Sumber } \\
\text { Daya }\end{array}$ & $\mathbf{V}$ & & $\mathbf{I}$ & 0 & $\begin{array}{l}\text { Kateg } \\
\text { ori } \\
\text { komp } \\
\text { etitif }\end{array}$ & $\begin{array}{l}\text { Kin } \\
\text { erja }\end{array}$ & $\begin{array}{c}\text { Katego } \\
\text { ri } \\
\text { SWOT }\end{array}$ \\
\hline \multirow[t]{3}{*}{1} & $\begin{array}{l}\text { Pembiayaa } \\
\mathrm{n}\end{array}$ & & & & & & & \\
\hline & $\begin{array}{l}\text { Investasi } \\
\text { sarana dan } \\
\text { prasarana }\end{array}$ & $\mathrm{Y}$ & $\mathrm{Y}$ & $\mathrm{Y}$ & 4 & $\begin{array}{l}\text { Keung } \\
\text { gulan } \\
\text { Berkel } \\
\text { anjuta } \\
\text { n }\end{array}$ & $\begin{array}{c}\text { Diat } \\
\text { as } \\
\text { Nor } \\
\text { mal }\end{array}$ & $\begin{array}{c}\text { Kekuat } \\
\text { an dan } \\
\text { kompet } \\
\text { ensi } \\
\text { khusus } \\
\text { jangka } \\
\text { panjan } \\
\text { g }\end{array}$ \\
\hline & $\begin{array}{l}\text { Anggaran } \\
\text { pengemban } \\
\text { gan guru }\end{array}$ & $\mathrm{Y}$ & $\mathrm{Y}$ & $\mathrm{N}$ & 3 & $\begin{array}{l}\text { Keung } \\
\text { gulan } \\
\text { Berkel } \\
\text { anjuta } \\
\text { n }\end{array}$ & $\begin{array}{c}\text { Diat } \\
\text { as } \\
\text { Nor } \\
\text { mal }\end{array}$ & $\begin{array}{c}\text { Kekuat } \\
\text { an atau } \\
\text { kelema } \\
\text { han }\end{array}$ \\
\hline \multirow[t]{3}{*}{2} & $\begin{array}{l}\text { Penilaian } \\
\text { Pendidikan }\end{array}$ & & & & & & & \\
\hline & $\begin{array}{l}\text { Informasi } \\
\text { dan criteria } \\
\text { penilaian }\end{array}$ & $\mathrm{Y}$ & $\mathrm{Y}$ & $\mathrm{N}$ & 2 & $\begin{array}{c}\text { kesei } \\
\text { mban } \\
\text { gan }\end{array}$ & $\begin{array}{l}\text { Nor } \\
\text { mal }\end{array}$ & $\begin{array}{c}\text { Kekuat } \\
\text { an atau } \\
\text { kelema } \\
\text { han }\end{array}$ \\
\hline & $\begin{array}{l}\text { Laporan } \\
\text { hasil } \\
\text { penilaian } \\
\text { pembelajar } \\
\text { an }\end{array}$ & $\mathrm{Y}$ & $\mathrm{N}$ & $\mathrm{N}$ & 1 & $\begin{array}{c}\text { kesei } \\
\text { mban } \\
\text { gan }\end{array}$ & $\begin{array}{l}\text { Nor } \\
\text { mal }\end{array}$ & $\begin{array}{c}\text { Kelem } \\
\text { ahan }\end{array}$ \\
\hline \multirow[t]{3}{*}{3} & $\begin{array}{l}\text { Pendidik } \\
\text { dan Tenaga } \\
\text { Kependidik } \\
\text { an, }\end{array}$ & & & & & & & \\
\hline & $\begin{array}{l}\text { Guru } \\
\text { dengan } \\
\text { kompetensi } \\
\text { yang sesuai }\end{array}$ & $\mathrm{Y}$ & $\mathrm{Y}$ & $\mathrm{N}$ & 2 & $\begin{array}{c}\text { kesei } \\
\text { mban } \\
\text { gan }\end{array}$ & $\begin{array}{l}\text { Nor } \\
\text { mal }\end{array}$ & $\begin{array}{c}\text { Kekuat } \\
\text { an atau } \\
\text { kelema } \\
\text { han }\end{array}$ \\
\hline & $\begin{array}{l}\text { Kepala } \\
\text { sekolah } \\
\text { dengan }\end{array}$ & $\mathrm{Y}$ & $\mathrm{N}$ & $\mathrm{N}$ & 1 & $\begin{array}{l}\text { kesei } \\
\text { mban } \\
\text { gan }\end{array}$ & $\begin{array}{l}\text { Nor } \\
\text { mal }\end{array}$ & $\begin{array}{c}\text { Kekuat } \\
\text { an atau } \\
\text { kelema } \\
\text { han }\end{array}$ \\
\hline
\end{tabular}

Keterangan : $\mathrm{Y}=$ ya; $\mathrm{N}=$ tidak; $1=$ sumber daya tidak dikelola; 2 = sumber daya cukup dikelola; 3 = sumber daya dikelola; $4=$ sumber daya dikelola dengan baik. Setelah melakukan analisis factor internal sekolah dengan menggunakan VRIO maka dilakukukan analisis factor internal.

Tabel 4 : Analisis factor ekternal Sekolah

\begin{tabular}{|c|c|c|}
\hline No & Aspek & Keterangan \\
\hline 1 & Peraturan dan Regulasi & 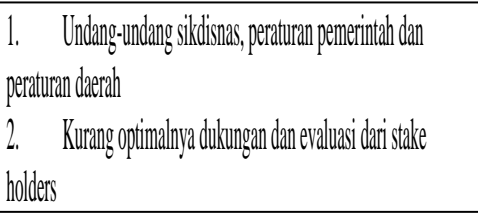 \\
\hline 2 & $\begin{array}{ll}\text { Kelembagaan } & \text { ataul } \\
\text { yayasan pengelolal }\end{array}$ & 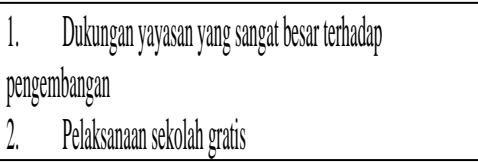 \\
\hline 3 & $\begin{array}{ll}\text { Akses } & \text { terthadap } \\
\text { pembiagyan } & \\
\end{array}$ & 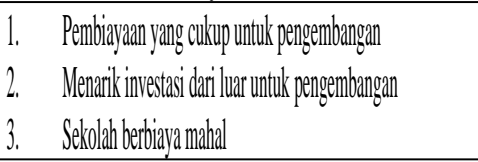 \\
\hline 4 & $\begin{array}{l}\text { Teknologi informasi dan } \\
\text { komunikasi }\end{array}$ & 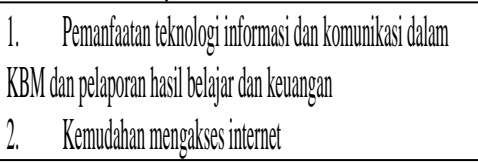 \\
\hline 5 & kebjijkan & $\begin{array}{l}\text { 1. Dukungan pemerintah dareah dalam mengembangkan } \\
\text { sekolah } \\
\text { 2. Kegiatan ekstrakuninkuler yang kurang mendukung }\end{array}$ \\
\hline 6 & Lokasis sekolah & Lokasi yang strategis dan kemudahan akses Lokasi \\
\hline 7 & Kebutuhan sekolalah & 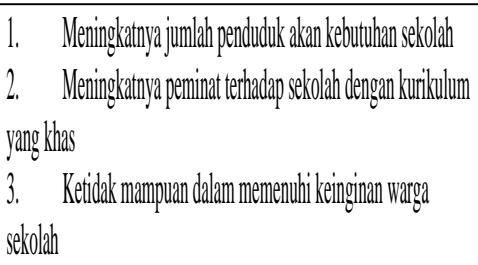 \\
\hline
\end{tabular}

\section{HASIL DAN PEMBAHASAN}

\section{A.Posisi Strategis Rencana Pengembangan sekolah Islam Terpadu}

Faktor internal dan eksternal yang telah ditentukan, selanjutnya akan diolah untuk mengetahui posisi strategis rencana pengembangan sekolah islam terpadu. Proses selanjutnya adalah :

Tabel 5 : Skor evaluasi faktor internal sekolah 


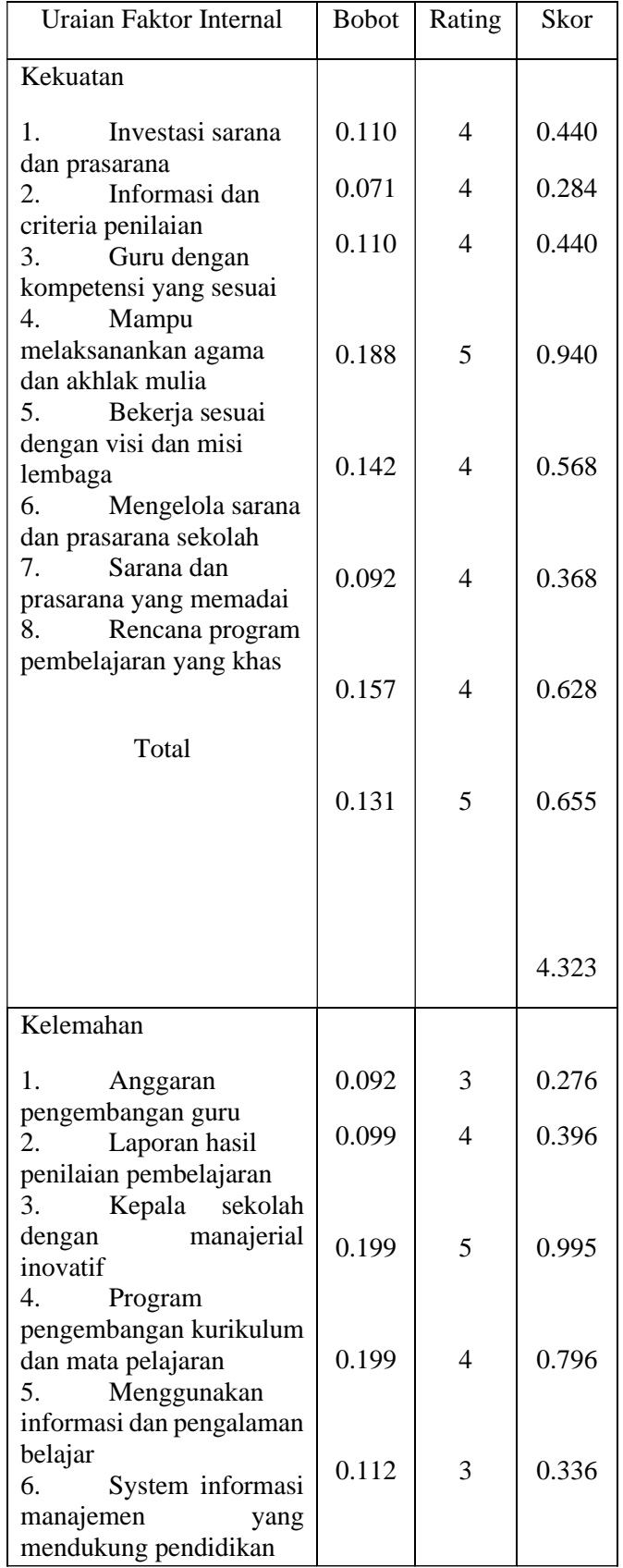

Tabel 6 : Skor evaluasi faktor eksternal sekolah

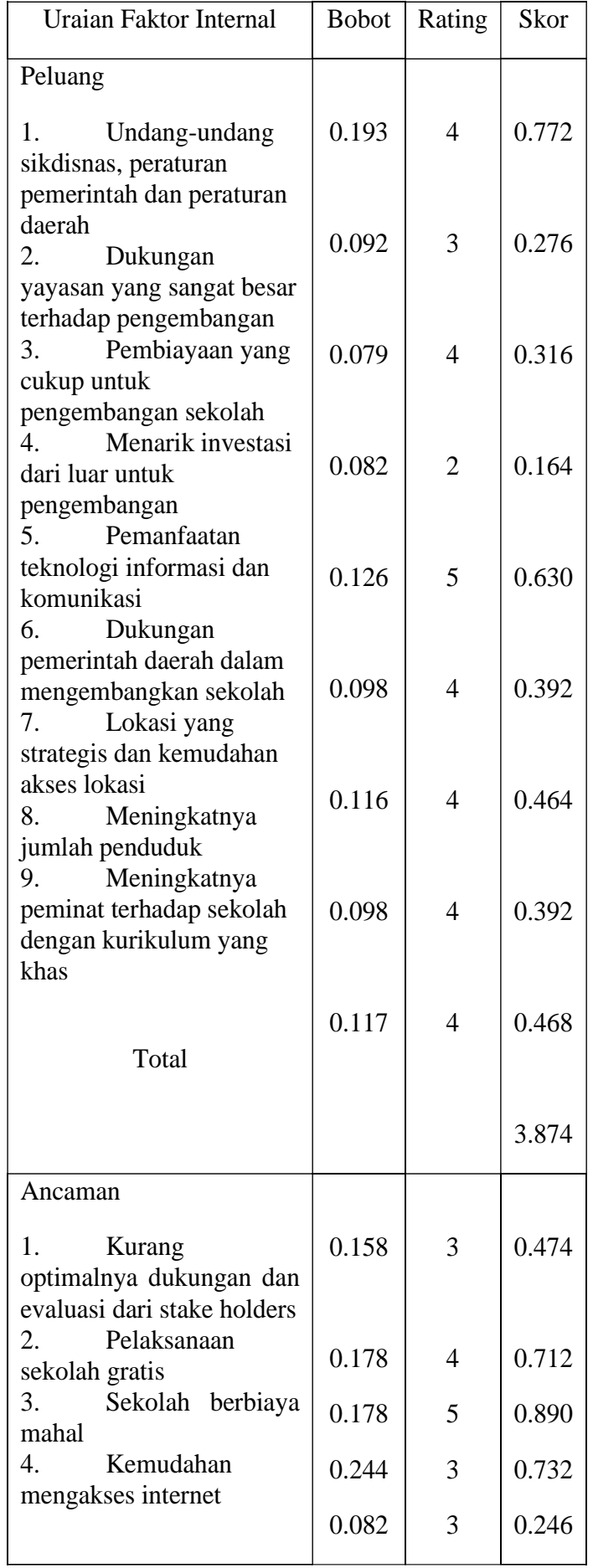

dari hasil perhitungan ditentukan posisi pengembangan sekolah dengan matrik SPACE 


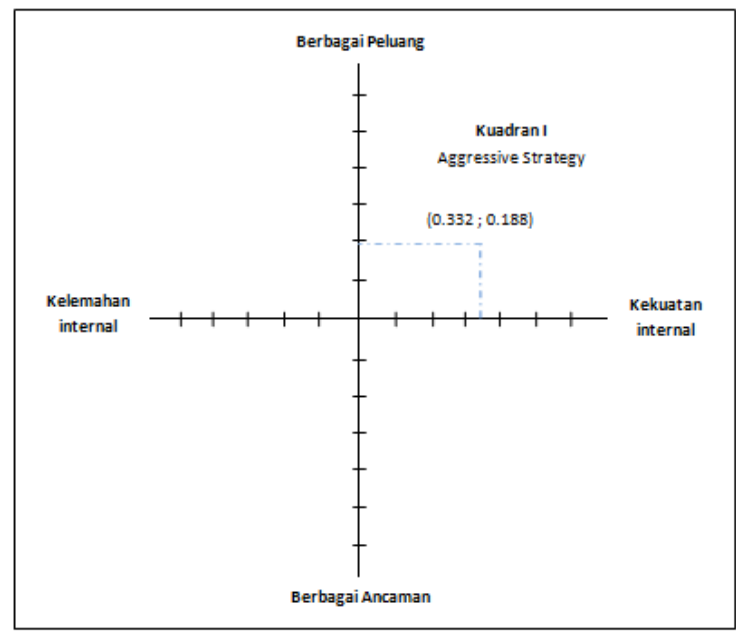

Gambar 2 : Matrik SPACE penentuan strategi

Berdasarkan hasil dari penentuan strategi ada pada kuadran I maka ditetapkan strategi aggresif yaitu memanfaakan kekuatan untuk meraih peluang

\section{B.Perumusan Strategi Pengembangan sekolah}

Strategi pengembangan sekolah disusun dengan mempertimbangkan faktor internal maupun eksternal yang telah disusun. Perumusan strategi pada penelitian ini mempergunakan metode analisis SWOT (selengkapnya disajikan pada Tabel 7).

Tabel 7 : Perumusan strategi pengembangan sekolah

\section{KESIMPULAN}

Perencanaan pengembangan sekolah berbasis sumber daya merekomendasikan pengembangan strategis sekolah dengan 4 strategi alternatif yaitu :

1. Peningkatan sarana dan prasarana untuk mendukung KBM

2. Memanfaatkan teknologi untuk mendukung kegiatan

3. Meningkatkan kemampuan dan inovasi seluruh sumber daya

4. Mengembangkan kurikulum yang khas tentang agama dan sains

menentukan langkah untuk menentukan grand strategi dan elemen yang berpengaruh dalam pengembangan sekolah dalam gambar 3 berikut

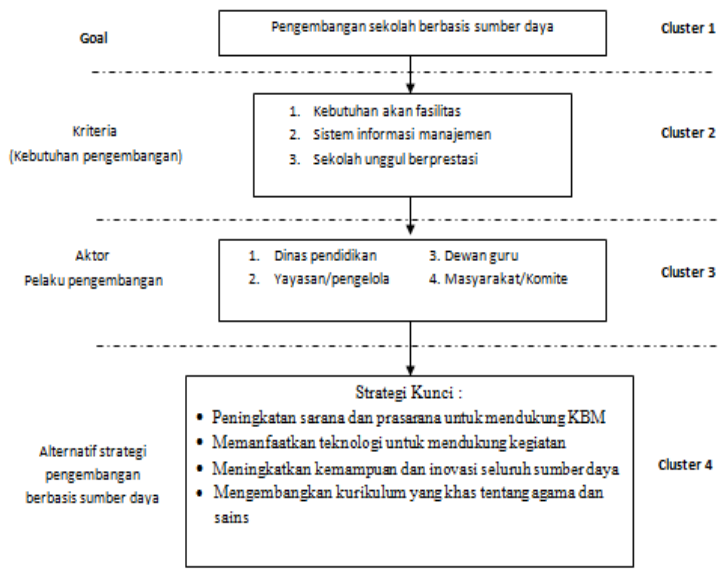

Gambar 3 : Grand Strategi pengembangan sekolah berbasis sumber daya

\begin{tabular}{|c|c|c|c|}
\hline & \multicolumn{2}{|c|}{ Faktor-faktor Internal } \\
\hline & & Strengths (S) & Weakness (W \\
\hline & & $\begin{array}{l}\text { S1 Investasi } \\
\text { sarpras } \\
\text { S2 Informasi dan } \\
\text { penilaian } \\
\text { S3 kompetensi } \\
\text { guru } \\
\text { S4 Agama dan } \\
\text { akhlak mulia } \\
\text { S5 Visi dan misi } \\
\text { lembaga } \\
\text { S6 Mengelola } \\
\text { sarpras } \\
\text { S7 Sarpras yang } \\
\text { memadai } \\
\text { S8 Pembelajaran } \\
\text { yang khas }\end{array}$ & $\begin{array}{l}\text { W1 Anggaran } \\
\text { guru } \\
\text { W2 Laporan has } \\
\text { penilaian W3 } \\
\text { Kepsek } \\
\text { inovatifProgram } \\
\text { W4 } \\
\text { pengembangan } \\
\text { kurikulum W5 } \\
\text { Menggunakan } \\
\text { informasi W6 } \\
\text { Sistem informas } \\
\text { W7 Evaluasi } \\
\text { pembelajaran }\end{array}$ \\
\hline \multirow{3}{*}{ 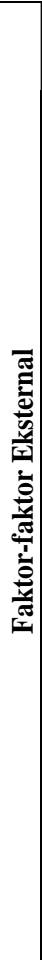 } & $\begin{array}{l}\text { Opportunity } \\
\text { (O) }\end{array}$ & SO Strategi & WO Strategi \\
\hline & $\begin{array}{l}\text { O1 } \\
\text { Dukungan } \\
\text { pemerintah } \\
\text { O2 } \\
\text { Dukungan } \\
\text { yayasan } \\
\text { O3 } \\
\text { Pembiayaan } \\
\text { pengembanga } \\
\text { n } \\
\text { O4 Menarik } \\
\text { investasi } \\
\text { O5 } \\
\text { Pemanfaatan } \\
\text { teknologi } \\
\text { O6 } \\
\text { Dukungan } \\
\text { kota Depok } \\
\text { O7 Lokasi } \\
\text { yang strategis } \\
\text { O8 Jumlah } \\
\text { penduduk } \\
\text { O9 } \\
\text { Meningkatny } \\
\text { a peminat }\end{array}$ & $\begin{array}{l}\text { • Peningk } \\
\text { atan sarana dan } \\
\text { prasarana untuk } \\
\text { mendukung } \\
\text { KBM (S1, S2, } \\
\text { SO3, O1,O2, O4, } \\
\text { O6) } \\
\text { • Memanf } \\
\text { aatkan teknologi } \\
\text { untuk } \\
\text { mendukung } \\
\text { kegiatan (S3, S7, } \\
\text { S8, O5) } \\
\bullet \quad \text { Meningk } \\
\text { atkan } \\
\text { kemampuan dan } \\
\text { inovasi seluruh } \\
\text { sumber daya } \\
\text { (S5, S7, O2, O3, } \\
\text { O5) } \\
\bullet \quad \text { Mengem } \\
\text { bangkan } \\
\text { kurikulum yang } \\
\text { khas tentang } \\
\text { agama dan sains } \\
\text { (S4, S5, O2, O5) } \\
\text { ST Strateqi }\end{array}$ & \\
\hline & Treaths (1) & SI Strateg1 & WT St \\
\hline
\end{tabular}




\section{DAFTAR PUSTAKA}

Gujrati R. 2013. The Role Of Sme's In The Economic Development. Masters International Journal of Management Research and Development 1(1): 86-97.

Marimin. 2004. Teknik dan Aplikasi Pengambilan Keputusan Kriteria Majemuk. Jakarta : Grasindo.

Umaedi, Manajemen Peningkatan Mutu Berbasis Sekolah, Direktur Pendidikan

Menengah dan Umum, April, 1999: 4 